\title{
A Multi-source Data Based Analysis Framework for Urban Greenway Safety
}

\author{
Junyi SU, Weida YIN, Renfei ZHANG, Xiyao ZHAO, Olivier Ngoko CHINKAM, Hanwen ZHANG, Fei LI, Le KANG
}

\begin{abstract}
As a green lining open space, greenways are closely related to the life of urban residents. At present, reports of crimes occurring in greenways are emerging in an endless stream. In order to explore the factors affecting greenway safety, this study, under the guidance of CPTED theory, conducts research by means of big geodata. Three representative greenways in Beijing urban area-the Northwest Tucheng greenway, Second Ring Road greenway and the Three Mountains and Five Gardens greenway-are taken as the research objects. Through the utilization of big geodata information from each platform, including street view analysis, POI analysis, and sports activity data analysis, four factors including space boundary, maintenance, public surveillance and activity support are considered comprehensively, and important influencing factors are selected to construct the analysis framework for urban greenway safety. The results showed that the greenway with high safety has the characteristics of low density of arbor shrubs, low enclosure degree of walls, low distribution density of various buildings, high traffic flow and high frequency of use. The feasibility of the analysis framework is verified by the current situation of greenway safety, so as to provide scientific and reasonable technical support for the construction of safe urban greenways.
\end{abstract}

Keywords: big geodata; data analysis; greenway safety; urban greenway

\section{INTRODUCTION}

As a linear open space along a natural corridor or which has been transformed for recreational use [1], a greenway can amplify the effect of a single block of green space, and is a multi-functional comprehensive green space system. The term greenway first appeared in 1959 and was used by Whyte [2]. In 1887 Frederick Law Olmsted designed and was responsible for the construction of the first greenway known as the Boston greenway system. In 1987, it was officially approved by the President's Commission on American Outdoor for the first time [3]. The urban greenway attaches more importance to connecting various open spaces of the city, including the city's landscape axes, urban arterial roads, and riverbanks, to form an orderly whole. At present, the research on urban greenways is mainly focused on the planning and design features of greenways based on the constructions of urban ecological network, lacking human-oriented pedestrian safety research. Due to the influence of space design openness, a large number of private spaces in some parks and greenways provide effective shelters for various criminal activities [4]. Besides, greenways contain beautiful environments and many trees, which can, more than ordinary city streets, attract citizens to sightsee, walk and practise fitness routines. This however provides an opportunity for some criminal activities such as theft [5]. There are endless reports of crimes happening in greenways [6]. In view of this phenomenon, Behavioural Scenario theory, Street Eye theory, Defensible Space theory and Crime Prevention through Environmental Design (CPTED) theory have been produced successively in Europe and the United States [7, 8]. In the 1960s, Jane Jacobs put forward the simple criminology theory and pointed out that a higher degree of natural monitoring could create a safe environment [9]. In the 1970s, Jeffery and Newman almost simultaneously proposed the CPTED theory [10] and put forward the strategy of space design from the perspective of crime prevention. Currently, the third-stage CPTED concept is characterized by the reprogramming of urban space through digital means; the green and sustainable urban physical layer design is carried out within this framework [11, 12]. The potential connection between greenways and crime cases and how to create a safer space through urban greenway design [13] have also become the focus of research on reducing crime incidents.

In the 21 st century, with the rapid development of ICT (Information and Communication Technology) represented by social networks, street view maps and location-based services, cities are constantly generating and transmitting massive data [14-16] with huge scale and great value $[17,18]$. Security analyses of urban environment through big data presently focus mainly on the analysis of human behaviour and the evaluation of the environment itself [19]. In these two aspects, big data has huge advantages. These can be developed as specific assessment tools to make a more reasonable positive response to the problem [20] and adapt to multi-scale analysis needs [21]. Many scholars have used big data analysis technology to evaluate the quality of urban open green spaces, and conducted a series of tool development and empirical studies on the correlation between environment and violent crime, residents' health, sports activities and traffic behavior [22-24]. Image data, such as street views and social media photos, are mostly used for image machine recognition to obtain the assessment of environmental quality [25]. Geospatial data, such as geographic coordinates, movement track, bus swipe card data, are mostly used for geospatial analysis [26], hence the relationship between human behavior and space is obtained. These application methods are also applicable to environmental safety analysis that requires the analysis of people and the environment. However, as an important special project of urban environmental design [27], there are few theoretical studies on the safety of greenways.

Using big geodata to study the relationship between urban environmental design and crime plays an important role in improving environmental security. By means of multi-source data, including street view, sports software and Baidu online maps, this research comprehensively considers the influencing factors of greenway safety from the four aspects of space, management, society and environment, constructs a greenway safety evaluation framework, and analyses greenway environment and safety from multiple perspectives. This can make up for the deficiencies in this field and provide certain guiding principles for the construction of safe greenways. 


\section{RESEARCH OBJECT}

After the reform and opening up in 1979, the proportion of urban green space in China increased significantly. Since 2010, China's greenway has entered the first round of actual construction. Beijing plans to build 992 kilometers of healthy greenway in 3-5 years [28]. This study takes three greenways within the fifth Ring Road in Beijing as the research object, namely, the Second Ring Road greenway, Northwest Tucheng greenway and the Three Mountains and five Gardens greenway.

The Second Ring Road greenway is an urban waterfront greenway, with a total length of $34.6 \mathrm{~km}$, built on the support of the Beijing moat [29]. The greenway connects the parks and historical sites along the road including Houhai Park, Ditan Park, Yonghegong Temple, etc,; integrating the roadside green space and waterfront green space on both sides of the second Ring road and moat to form a green corridor of water and green space.

The total length of Northwest Tucheng greenway is 8.7 $\mathrm{km}$. It connects the Yuandadu Ruins Park, Madian Park, Chinese Ethnic Park and other parks' green spaces. Moreover, they are close to residential areas. This greenway currently has a mature green space and road system.

The Three Mountains and Five Gardens greenway, mostly used as land for road and park land [30], is $36.1 \mathrm{~km}$ in length. It is the municipal greenway connecting the largest number of historic gardens and scenic spots in Beijing. The term "Three Mountains and Five Gardens" refers to the generic name of all historical imperial parks and gardens in the western suburbs of Beijing [31]. The connection between the greenway and the scenic spots has enhanced the accessibility of the scenic spots. A green transportation network has been formed as a result.

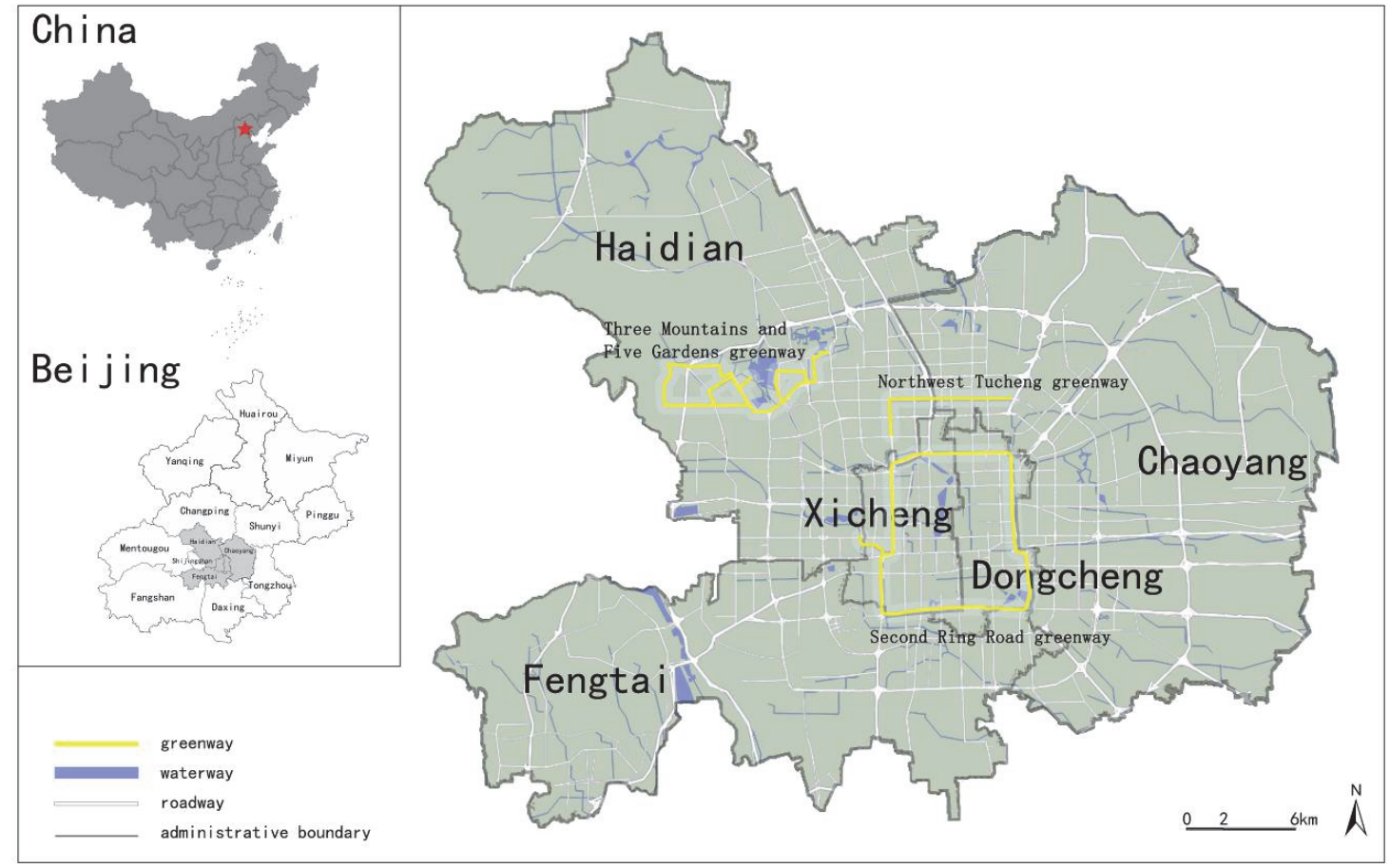

Figure 1 Greenway position

\section{RESEARCH METHOD}

According to CPTED theory, crime prevention measures contain six elements: target hardening, image/maintenance, public surveillance, activity support, territoriality and access control $[32,33]$. Target hardening denotes strengthening protection measures for specific targets, such as building walls and other means; image is the external condition that the space shows; public surveillance means that in densely populated areas, the surveillance factors are strong and the possibility of crime is low; activity support refers to the addition of commercial facilities, etc., to avoid the appearance of decay and chaos; territoriality and access control refer to the ownership of space and the identity audit of users, which is mainly aimed at buildings and has a weak correlation with greenways. Therefore, this study only analyzes four elements.

Based on the actual use characteristics of greenways, the greenway with transparent boundary is better [34, 35], so the target intensification factor is transformed into the space boundary. To sum up, the study divided the factors affecting the safety of greenways into four aspects: space boundary, maintenance, public surveillance, and activity support. Multiple platforms such as Baidu Street View, Keep software and Baidu online map were used as data sources to establish a multi-level analysis framework and to evaluate the safety of greenways. Space boundary factors include vegetation density and wall height. A well space design can improve security in the green space [36], since it can improve the ground visibility by reducing the heights of shrubs and fences $[37,38]$ as well as lowering the density of plants [39]. The maintenance factor is reflected in the vegetation maintenance status. The green space which is trimmed neatly by formal design is safer than the green space which looks more natural $[40,41]$. Public surveillance factors include the monitoring intensity and human activity. A high degree of social monitoring and dense activity crowd can bring tourists a sense of security 
[42-44]. Activity support factor is reflected by the density of points of interest (POI). The implantation of POI is conducive to increasing human activities, creating a good security environment, and achieving support for crime prevention [45].

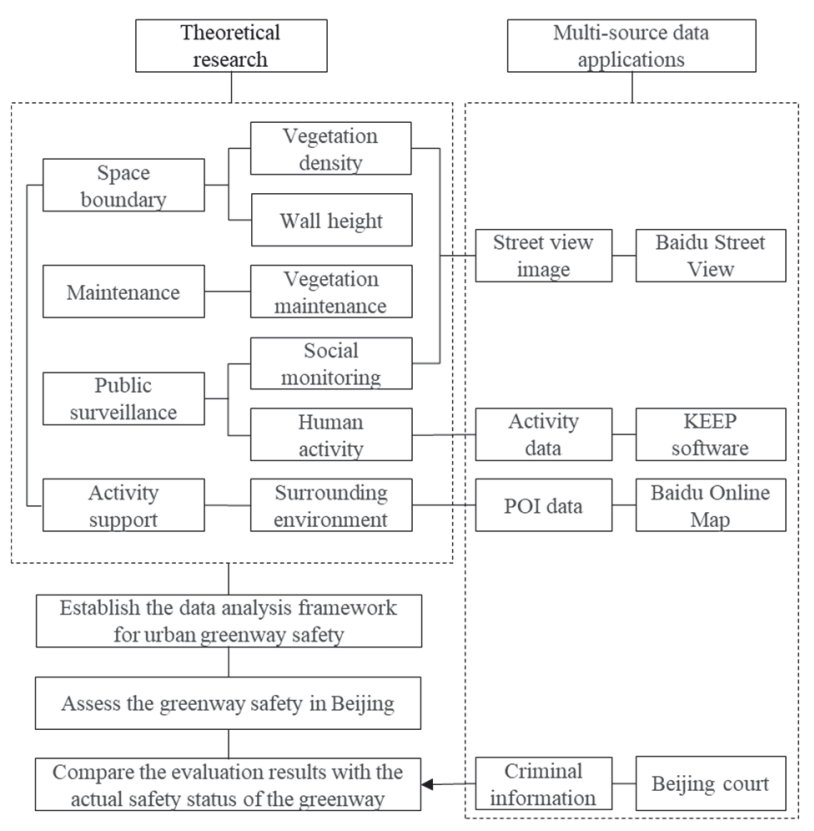

Figure 2 Technical route

Among them, Baidu Street View can obtain the greenway street view, and analyse the vegetation density, wall height, monitoring intensity and vegetation maintenance status [46-49]. Keep software can obtain the route and frequency of crowd activities and analyse the intensity of human activities. Baidu online map can obtain the types of POI and geographical location.

\subsection{Analysis Framework for Urban Greenway Safety}

Based on CPTED theory and urban greenway characteristics, four first-level indexes of the safety analysis framework are selected, including space factor, management factor, social factor and environmental factor. After further clarified classification, six secondary indexes are determined, including green visibility, space boundary, vegetation maintenance, social monitoring, activity intensity and surrounding environment. Based on the factors above, the analysis framework is established.

The weight value of the index is calculated by Analytic Hierarchy Process (AHP), and the judgment matrix is constructed by discriminating and comparing according to the hierarchical relationship. First, the importance of the primary indexes is compared in pairs to obtain the weights of the four primary indexes, W1. Secondly, the secondary index judgment matrices are constructed to obtain the second-level weight of each index, and then the weight value is multiplied by the weight of the primary index to which it belongs to obtain the comprehensive weight of the secondary indexes, W2. To ensure the judgment matrices were scientific and accurate, this study invited 8 landscape architecture experts and related researchers to make independent judgments without interfering with each other. The 8 groups of judgment matrices obtained were comprehensively evaluated to find the weight values of each index (Tab. 1).

According to the analysis and calculation above, the evaluation model of the urban greenway security is established as follows:

$$
R V=\sum_{i=1}^{6} W_{i} B_{i}
$$

Table 1 The evaluation indexes of urban greenway space security

\begin{tabular}{|c|c|c|c|c|c|}
\hline $\begin{array}{c}\text { Primary indexes } \\
\left(W_{1}\right)\end{array}$ & secondary indexes & $\begin{array}{c}\text { Comprehensive } \\
\text { weight } W_{2}\end{array}$ & $\begin{array}{l}\text { Weight within the } \\
\text { degree }\end{array}$ & Index description & source \\
\hline \multirow{2}{*}{$\begin{array}{l}\text { Space boundary } \\
(0.37)\end{array}$} & Vegetation density & 0.21 & 0.55 & $\begin{array}{l}\text { the proportion of the remaining area except green } \\
\text { area (arbor and shrub) }\end{array}$ & $\begin{array}{l}\text { Baidu street } \\
\text { view }\end{array}$ \\
\hline & Wall height & 0.16 & 0.45 & $\begin{array}{l}\text { the proportion of the remaining area except the } \\
\text { fence and railing }\end{array}$ & $\begin{array}{l}\text { Baidu street } \\
\text { view }\end{array}$ \\
\hline $\begin{array}{l}\text { Maintenance } \\
(0.14)\end{array}$ & $\begin{array}{c}\text { Vegetation } \\
\text { maintenance }\end{array}$ & 0.14 & 1 & the neatness degree of vegetation trim & $\begin{array}{l}\text { Baidu street } \\
\text { view }\end{array}$ \\
\hline \multirow{2}{*}{$\begin{array}{l}\text { Public Surveillance } \\
\qquad(0.31)\end{array}$} & Social monitoring & 0.19 & 0.58 & the proportion of building and car area & $\begin{array}{l}\text { Baidu street } \\
\text { view }\end{array}$ \\
\hline & Human activity & 0.12 & 0.42 & the frequency of running & KEEP software \\
\hline $\begin{array}{c}\text { Activity Support } \\
(0.18)\end{array}$ & $\begin{array}{l}\text { Surrounding } \\
\text { environment }\end{array}$ & 0.18 & 1 & distribution density of POI & $\begin{array}{l}\text { Baidu Online } \\
\text { Map }\end{array}$ \\
\hline
\end{tabular}

There into $R V$ represents the evaluation value of the urban greenway environmental security; $W_{i}$ represents the weight of the $i$-th index; and $B_{i}$ represents the value of the $i$-th index. According to the evaluation value about environmental security of urban greenways, the higher the score value is, the higher the level of safety.

\subsection{Data Acquisition Method \\ 3.2.1 Street View Acquisition Method}

Based on the Big map data, this study obtained the data of three greenway road networks, and captured 459 sampling points at equal intervals with the assistance of Baidu street view API (Application Programming
Interface). The average sampling interval was about $150 \mathrm{~m}$. Street view is obtained by invoking Baidu street view panoramic static map (*) API query. By setting parameters such as image size, latitude and longitude coordinates, sending HTTP (Hypertext Transfer Protocol) requests to visit Baidu map panoramic static map service, developers can get the panoramic street view in various servers. (*http://api.map.baidu.com/panorama/v2?ak=ZSkOTpzIm wK2SbW4IOdgionLrv3d3p0X\&width $=1024 \&$ height $=50$ 0\&location=116.367339,39.982286\&fov=360).

Baidu map platform creates an application access code (AK); the AK replacement URL sample can get a specific URL. Next, input the line of sight direction of horizontal and vertical angles and viewpoints location data in the 
URL to grab every street view of sample points. Each picture contains the unique identifier of position point, longitude and latitude, view Angle and other information. In order to obtain the coverage of greening from a humanoriented perspective, the vertical Angle of sight is uniformly set as $0^{\circ}$, that is, the level view. Considering the location of each sampling point on the road and the form of adjacent parks and street networks, the horizontal visual Angle is $360^{\circ}$. Such a collection can form a comprehensive coverage of the built environment around the point of view, that is, panoramic pictures. Each panorama is $1024 \times 500$ pixels in size.

The panoramic static map obtained by Baidu map is a typical spherical panorama (Fig. 4). The SPHERE is the most common type of panorama, with an Angle range of $360 \times 180$. Since the data on both sides of the greenway is the focus of this study, the image distortion in perspective will make the detection result unsatisfactory. The spherical panorama therefore needs to be converted into a Cube panorama.

The panorama of the cubic image represents six faces, front, rear, left, right, up and down. Convert SPHE RE to CUBE droplet making use of a tool in KRPano, which can convert a spherical panorama into a cube panorama (Fig. 5 ). The street view map of corresponding directions on both sides of the road is selected from the six angles for further analysis.

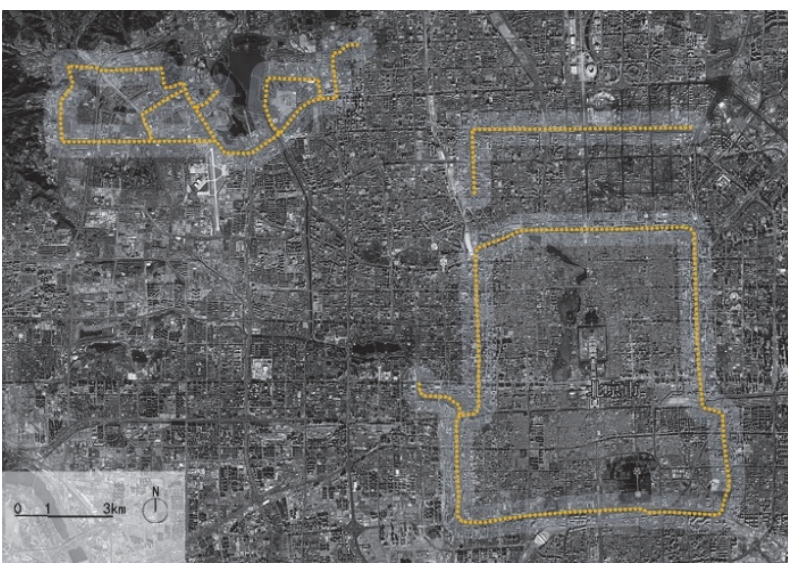

Figure 3 Street view sampling point distribution


Figure 4 Street view panorama



Street view panorama

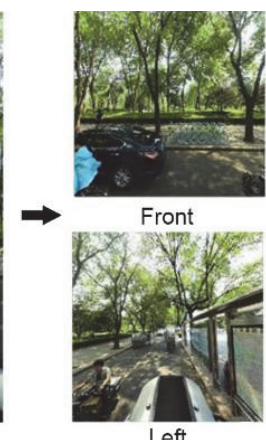

Left

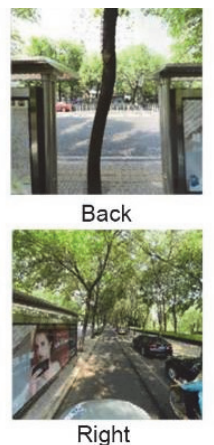

Figure 5 Street view panorama conversion example


Down

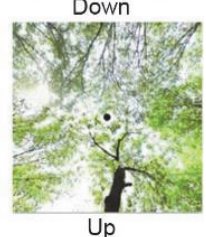

Up
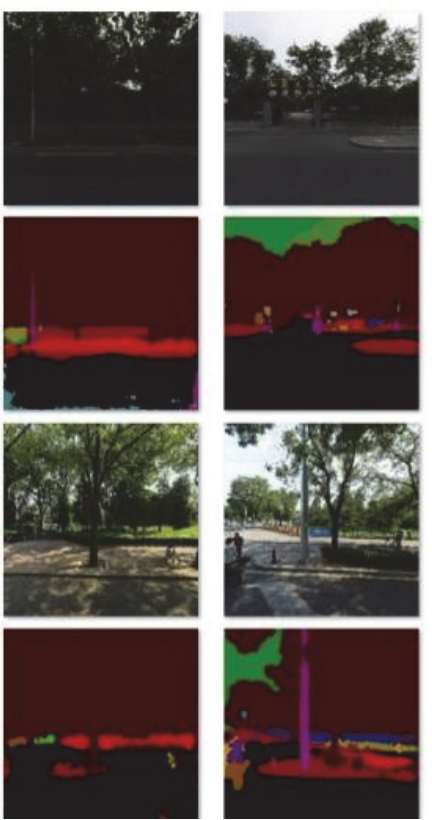

Figure 6 Spherical graph segmentation example 


Table 2 Semantic segmentation tag
\begin{tabular}{|c|c|c|c|c|c|c|c|c|}
\hline road & sidewalk & building & wall & fence & pole & traffic light & traffic sign & vegetation \\
\hline terrain & sky & person & rider & car & truck & bus & motorcycle & bicycle \\
\hline & & & & & & & & \\
\hline
\end{tabular}

Deep learning (semantic segmentation) was used to extract image features in the analysis of street green coverage. The pixel points in the picture are identified as tree, shrub, vehicle, railing and other elements (Tab. 2), and on this basis, the proportion of elements in each picture can be calculated.

Then modify the official code of tensor flow and execute "python deeplab_demo.py -i images -c checkpoints/deeplabv3_cityscapes_train_2018_02_06.tar. gz -o results" in the code path. Then enter the image path in images and the result path in results to get the image segmentation result (Fig. 6).

\subsubsection{POI Data Acquisition Method}

It is one of the research emphases to clarify the influence of different types of interest points on the crime rate. With the gradual denseness of road networks and diversification of building types, the urban spatial structure is also increasingly complex, bringing more complex social and built environments, and providing more opportunities for criminals to commit crimes.

The study extracted 5742 pieces of POI data including commercial services in the study area on Baidu map. Based on Guidelines of the General Office of the State Council on Accelerating the Development of Consumer Service Industries and Upgrading the Consumption Structure and the National Economical Industry Classification (GB/T4754-2002), POI data are classified and then checked through map recognition and field research. Finally, the data was divided into 5 middle and 15 small categories (Tab. 3).

\begin{tabular}{|c|c|c|c|}
\multicolumn{5}{|c|}{ Table 3 Classification table of interest points } & subclass & amount & rate \\
\hline class & Government agency, medical treatment, life service, automobile service & 1436 & $25.01 \%$ \\
\hline infrastructure & Business buildings, finance, companies and enterprises & 809 & $14.09 \%$ \\
\hline trade financing & Real estate community, Hotel & 563 & $9.80 \%$ \\
\hline accommodation & Entertainment, tourism, shopping, catering & 1870 & $32.57 \%$ \\
\hline Food and entertainment & Transportation facilities, Roads & 1064 & $18.53 \%$ \\
\hline traffic node & & 563 & 10 \\
\hline
\end{tabular}

In this paper, the kernel density tool in ArcGIS is used to discuss the spatial distribution characteristics of POI around the two greenways. The kernel density analysis method is mainly used to estimate the density degree of point elements in the spatial range with the help of moving grid units.

$D\left(x_{i}, y_{i}\right)=\frac{1}{u r} \sum_{i=1}^{u} k\left(\frac{d}{r}\right)$

where, $D\left(x_{i}, y_{i}\right)$ is the kernel density value at the spatial position $\left(x_{i}, y_{i}\right) ; r$ is the distance attenuation threshold; $u$ is the number of elements whose distance from position $\left(x_{i}\right.$, $y_{i}$ ) is less than or equal to $r$; the $k$ function represents the spatial weight function; $D$ represents the Euclidean distance between the current element point and the points $\left(x_{i}, y_{i}\right)$. Firstly, identify locations and extract data of interest points in the research area. Then, $200 \mathrm{~m}, 500 \mathrm{~m}$ and 1000 $\mathrm{m}$ were tested as the search radius, with the help of ArcGIS10.2 analysis tool. Compared with the results of kernel density analysis, the analysis results of $500 \mathrm{~m}$ were finally determined.

\subsubsection{Running Data Acquisition Method}

The study selected Keep platform as the data source to obtain GPS-based running data that can record the user's track, running mileage, pace and other running data [50], and collect the user's running route, corresponding times of use, creation time and so on. The data of Keep platform for nearly four years are selected to avoid the influence caused by different time periods or festivals.



Figure 7 Keep platform data
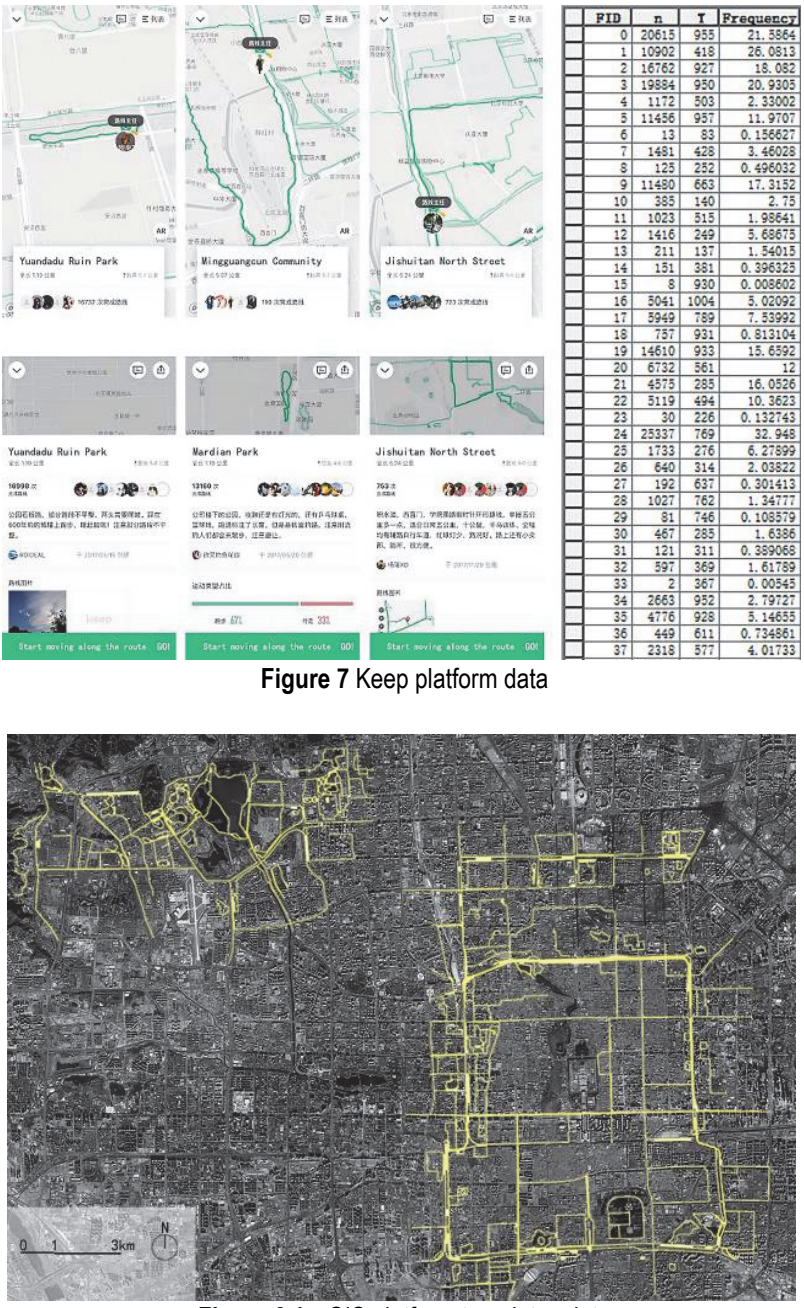

Figure 8 ArcGIS platform translates data 
A total of 207 routes were obtained in the study area, which were used more than 700.000 times. The data are translated into ArcGIS platform, containing the time when the route was created, $t$, and the number of times that the route was used, $\mathrm{n}$. In order to eliminate the difference in cumulative usage caused by different creation times, the study measured the frequency of route usage from the average daily usage, $f$, and obtained the kernel density map of human activities, which showed the relative utilization rates of the three greenways in different sections.

\subsubsection{Crime Data acquisition method}

According to the three months of criminal information published in the Beijing Court Trial Information Network from 2019.10.01 to 2020.01.01, a total of 1,720 civil and criminal cases related to greenways in the fifth ring road of Beijing were extracted, including motor vehicle traffic accident liability disputes, endangering public safety, intentional injury, theft, robbery, compulsory indecency, traffic accidents and other crimes.

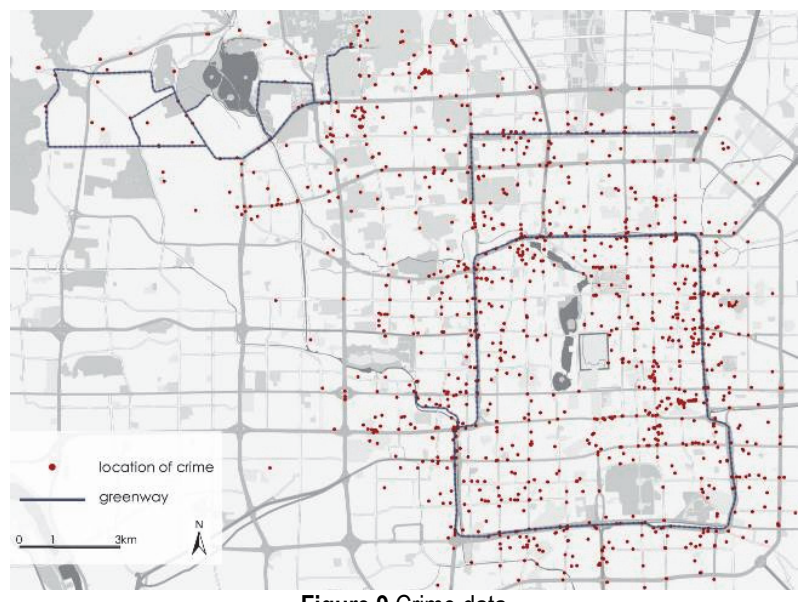

Figure 9 Crime data

In this study, Python language based web crawler and text analysis technology are adopted, and related words of information retrieval are combined to write programs to extract crime locations, and all crime locations within the study area are located in the ArcGIS platform (Fig. 9).

\section{RESULTS}

\subsection{Research Results of Space Boundary}

The green space in the northwestern section of the Second Ring Road greenway was relatively long and narrow, and the green area near the traffic node was significantly reduced. From the analysis of the spatial boundary, it could be seen that most of the green space boundary within the green road has no enclosing walls, and the openness was relatively high. The openness of Gulou Street and Mudanyuan area was relatively poor. According to the comparative analysis of the crime rate, it could be found that the crime rate is positively correlated with the height of the wall and the green area. That is, a block with poor openness is more likely to have a crime.

According to the comprehensive analysis, the safety grade of the greenway in Three Hills and Five Gardens changed significantly, the worst and best portions were distributed in this section. The overall vegetation coverage and spatial tightness were higher than those of the Second Ring Road greenway and the Northwest Tucheng greenway. In the Northwest Tucheng greenway, the overall safety of the section from Mingguang Bridge to Jiandemen is poor.

\subsection{Research Results of Activity Support Factors}

The points of interest show a distribution pattern along the road in space. The kernel density analysis method can be used to analyze the distribution pattern and distribution density of points of interest. In the Northwest Tucheng greenway, they shift towards the Beitucheng park. There are more interest points in the east and north of the Second Ring Road greenway, forming two strong agglomeration areas, with Anzhenmen and Jishuitan as the centres, respectively. The distribution of interest points in the Three Hills and Five Gardens greenway decreased significantly, and only two agglomeration points were formed near Zhongguancun and Xiangshan.

Different types of points of interest have different spatial distribution characteristics. Specifically, the interest points related to transportation and social service are mainly distributed along the road traffic nodes, while the interest points related to commercial finance, accommodation and catering are scattered. Although the distribution form of various types of living service industry are different, the main agglomeration centers are generally similar, mostly located in the northeast of the Second Ring Road greenway and at the Beitucheng west road, while the interest points in the Three Hills and Five Gardens greenway are less distributed.

Compared with the security situation, it can be found that the crime rate is high near the places with high population density and high mobility, such as supermarkets, shopping malls and public infrastructure closely related to people's life.

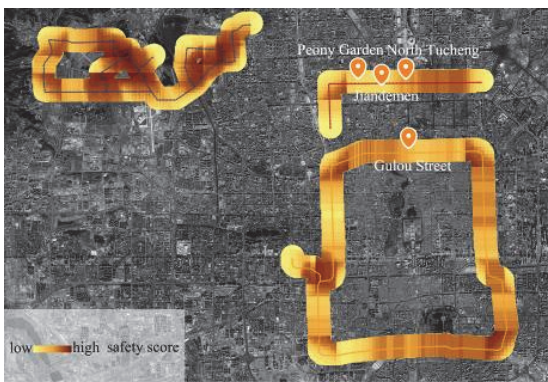

(a)

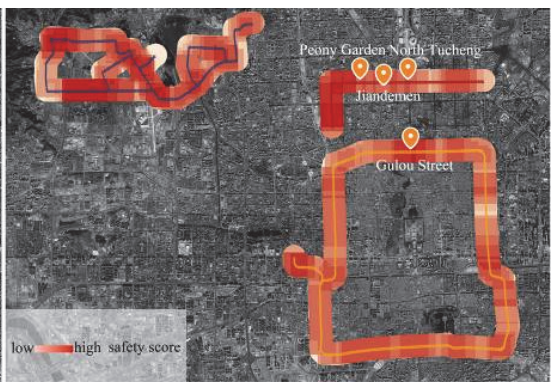



(c)

Figure 10 Space factor analysis: (a) Vegetation density; (b) Wall height; (c) Overlay analysis 


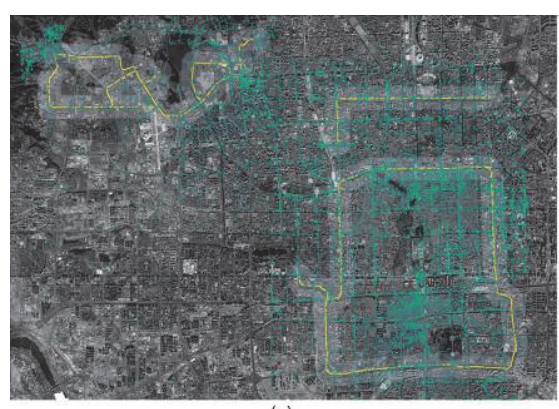

(a)

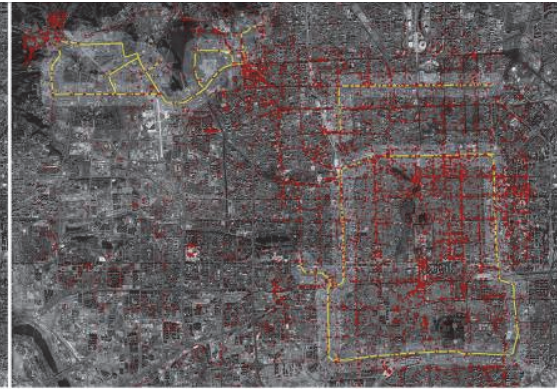

(b)

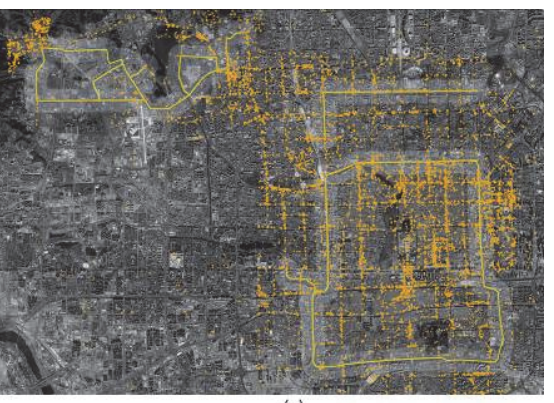

(c)

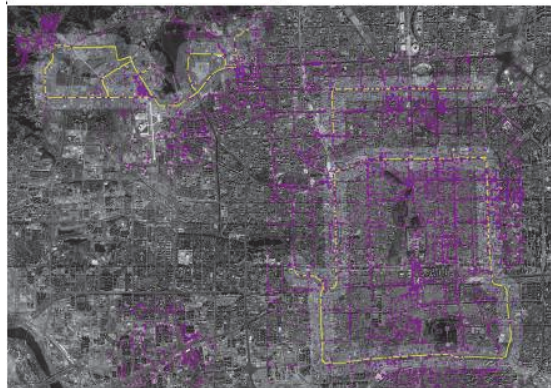

(d)

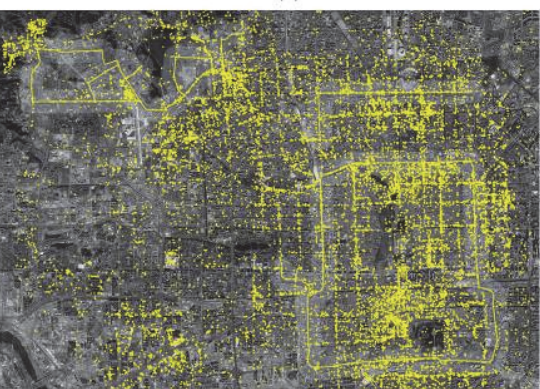

(e)

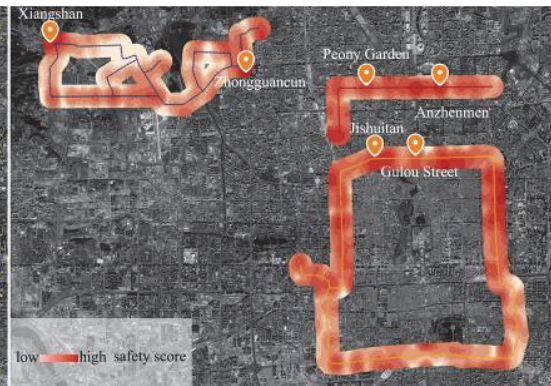

$6 \mathrm{~km} \stackrel{\text { N }}{(1}$

Figure 11 Kernel density analysis of points of interest: (a) Distribution of transportation POI; (b) Distribution of accommodation and catering POI; (c) Distribution of social service POI; (d) Distribution of commercial POI; (e) Distribution of total POI; (f) POI density diagram

\subsection{Research Results of Public Surveillance Factors}

The activity diagram states that the overall utilization rate of the Second Ring Road greenway and the Northwest Tucheng greenway is higher than that of the Three Hills and Five Gardens greenway. The score section of the Northwest Tucheng greenway between Jiandemen and Anzhenmen Station is higher. The score of the north
Second Ring Road greenway is relatively even, while that of Ditan park section is relatively high.

As can be seen from the social monitoring density map, Deshengmen bridge and Anzhenmen block have a strong degree of monitoring. The monitoring area of the Second Ring Road greenway is lower than that of the North Tucheng greenway, but the monitoring intensity is high, and the monitoring density of the Three Hills and Five Gardens greenway is the lowest.

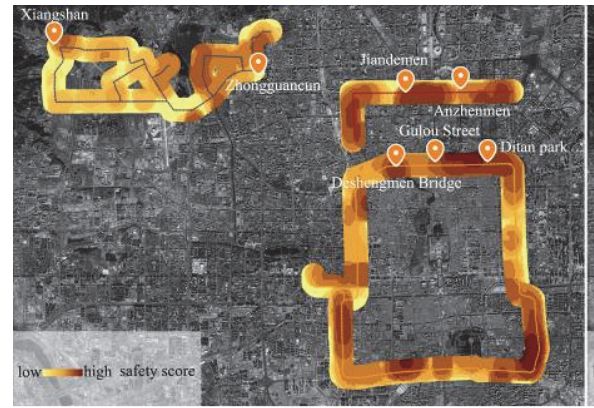

(a)



(b)

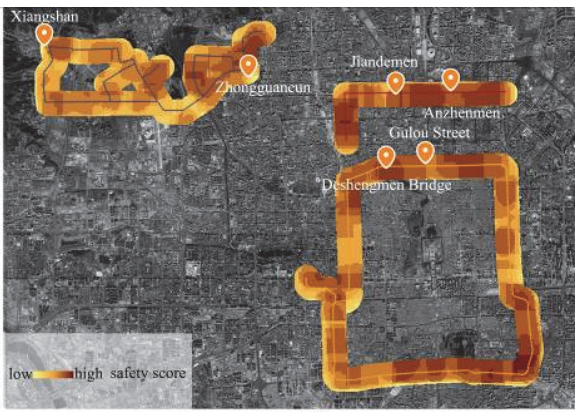

(c) ${ }_{6 \mathrm{~km}} \stackrel{\mathrm{N}}{1}$

Figure 12 Social factor analysis: (a) Social monitoring; (b) Human activity; (c) Overlay analysis

\subsection{Research Results of Maintenance Factors}

Through the analysis, it can be concluded that the degree of maintenance of vegetation in the Second Ring Road greenway is higher than that in the Northwest Tucheng greenway on the whole, while the degree of management in the Three Mountains and Five Gardens greenway varies greatly, with good management in the section near the urban area and neglect in the section near the shallow mountain area. The overall greening quality of the middle section of the Beitucheng greenway is poor. Due to the lack of normal pruning and maintenance of plants, the trees are uneven and the leaves are withered and yellow, which affects the normal growth of plants and leads to the decline of the quality of green space.

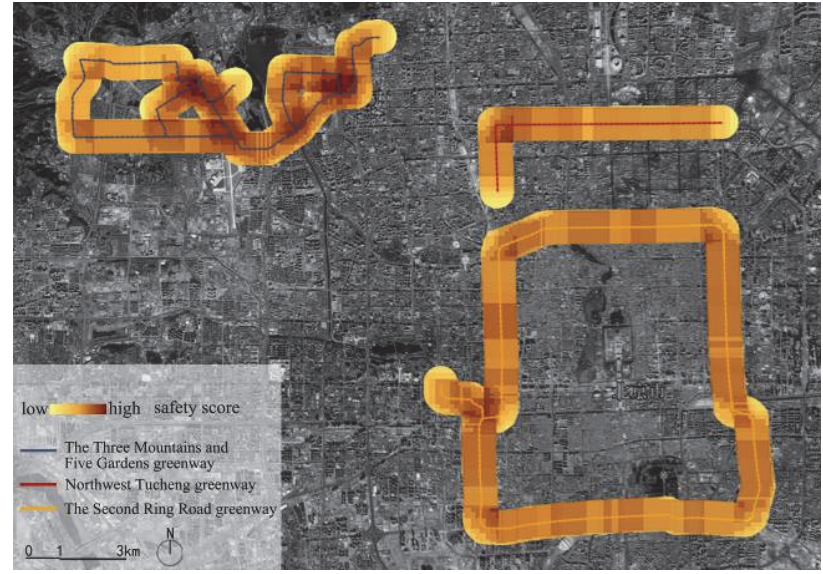

Figure 13 Vegetation maintenance analysis 
Combined with the comparative analysis of the crime rate, there is no strong correlation between the degree of vegetation construction and the occurrence of criminal events.

\subsection{Research Results of Weighted Overlay}

The greenway safety was evaluated by weighted superposition on the above four levels. From the results, it can be seen that the overall safety of the green roads in Three Hills and Five Gardens was relatively high. Only Zhongguancun has a lower level of safety, which is closely related to the dense distribution of interest points and high spatial confinement. The section with the highest safety is located at the east end of the Northwest Tucheng greenway and the west section of Three Hills and Five Gardens greeway. The place with lower safety is located at the junction of Beitucheng West Road and Beichen Road. Comparing the crime density map with the safety assessment, the areas with higher safety in the Second Ring Road greenway and Northwest Tucheng greenway have the characteristics of high monitoring density, sparse distribution of interest points, and open space.

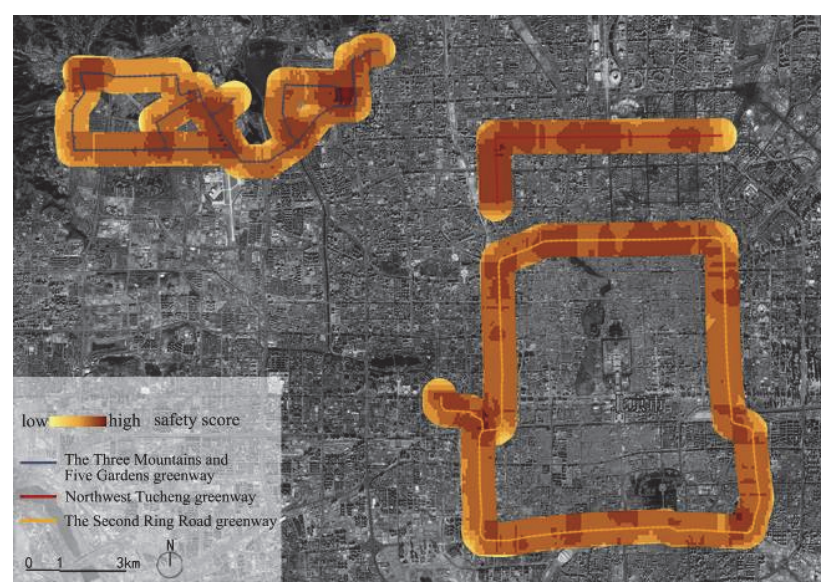

Figure 14 Safety management analysis

\section{DISCUSSION}

The method of analyzing and evaluating greenway safety based on the application of big data on the above three platforms is indisputable in terms of the coverage of research content and the amount of data for the evaluation of urban greenway safety. But at the same time, the data has shortcomings in crowd coverage, reliability of information sources and timeliness, etc., and it is difficult to overcome in a short term.

In the comparative analysis of space boundary factors and safety, it is found that the eastern section of the greenway in northwest Tucheng and the northeast section of the Second Ring Road greenway are relatively safe. The trees are loosely planted here, and the line of sight inside the green road is wide, without barriers by walls or railings. At the junction of Northwest Tucheng West Road and Beichen Road, there is a high degree of danger and high incidence of crime. The density of arbor shrubs in the greenway is high, and the border is blocked by a wall, so the line of sight is high. Among the three green roads, the space inside the Three Hills and Five Gardens greenway is relatively confined, but the crime rate is less than that of the Northwest Tucheng greenway and the Second Ring Road greenway. After analysis, it was found that the population density and tourist activity frequency around the Three Hills and Five Gardens greenway was low. It can be summarized that the crime scores are higher in the areas with higher spatial factors, that is, the areas with more confined spaces have frequent crimes, but some areas with low vegetation canopy are also frequent cases. It is speculated that the more open the space is, the safer it is. More detailed crime rate data can be obtained, and correlation analysis can be used to obtain the range of green coverage in areas with higher safety, and to guide the green quantity control of greenways.

Based on the results of POI analysis, it is found that the distribution of points of interest around the greenway is significantly affected by traffic, and is mostly concentrated on both sides of the main road. There are obvious differences in the distribution of interest points around the three greenways. There are many dense points of interest around the Second Ring Road greenway and the Northwest Tucheng greenway. There are few and scattered points of interest in the Three Hills and Five Gardens greenway. Comparing with the crime data, it can be seen that crime cases mostly occur in areas with dense points of interest. The more complicated the surrounding environment, the higher the frequency of crime. This is very different from the expected result under the "Street Eye" theory. Street Eye theory focuses more on the importance of city surveillance, and the occurrence of crime within the city is more relevant to the human concentration area. However, POI data also have shortcomings. In scenic spots, campuses and other large areas, POI distribution is sparse, which will lead to misidentification of POI density.

Based on the analysis of public surveillance factors, the crowd tends to run in or near the park, and a good sports environment will improve the safety of the park to a certain extent. The Northwest Tucheng greenway is more dominant than the Second Ring Road greenway at this level. The number of sports participants running from Jiandemen to Anzhenmen in the green road of Beitucheng is large. Moreover, the distribution density of external service buildings and the flow of people and vehicles is also large, thereby increasing the safety of tourists. The number of runners in the section from Fuchengmen to Fuxingmen on the Second Ring Road is small, and the external service buildings are sparsely distributed. These data also have their limitations; they naturally have certain group selectivity for mining big data under sports software. They exclude some groups such as the elderly who are not used to recording with sports software, and also have certain data deficiencies. However, based on the basic judgment of people's environmental preferences, the analysis results still have credibility.

Comparing the maintenance factor and the crime rate data, the results show that the management level is not relevant to greenway safety. Therefore, it is not objective to rely solely on the degree of vegetation pruning as a criterion for safety management. A more scientific analysis would be possible with access to the locations and numbers of sanitation and security personnel.

Big geodata helps to analyze the safety of urban greenways, and then provides a certain reference for the upgrading and safety improvement of greenways in the future. At the same time, it can promote the sustainable and healthy development of urban greenway systems and has good research prospects. Relying on the big data platform is conducive to larger-scale security analysis, and can be incorporated into a wider range of data sources to form a 
more scientific and reasonable analysis system. This method can also be used to evaluate urban greenway accessibility, intensity of use, and landscape performance. The current research team is constrained by the limited access to big data. In the future, if the verification data can be supplemented and enhanced, the accuracy of the research results will be further improved, in order to form a more perfect urban greenway research system.

\section{CONCLUSION}

The classification and extraction of various big data and geospatial system analysis of factors that cause greenway safety such as combining various parameters of space, environment and sociology to provide a systematic method for evaluating urban greenway safety and empirical research-was conducted on the representative greenways in the 5th Ring Road of Beijing. Through empirical research, it was found that greenways with high safety have the characteristics of low density of arbor shrubs, low enclosure degree of walls, low distribution density of various buildings, high traffic flow and high frequency of use.

The article opens up a new perspective in research methods of urban green space security, and draws on a variety of big geodata types, such as street view map, interest point and running data, which are summarized and connected with green space safety assessment. The parameters provided are suitable for determining and evaluating the security status and future simulation of urban greenways at various spatial scales. This basically confirms the reliability and effectiveness of the evaluation systems. This study is applicable to mega-cities, large cities and medium-sized cities where a certain number of greenways have been built and the quality and safety of greenways need to be improved to meet people's recreational and aesthetic needs. This research can provide more scientific and reasonable technical support and services for urban greenway planning and construction.

\section{Acknowledgements}

This work was supported by Beijing Natural Science Foundation (8172034), General Project of Teaching Research of Beijing Forestry University in 2020 (BJFU2020JY011) and National Natural Science Foundation of China (51978050).

\section{REFERENCES}

[1] Little, C. (1990). Greenways for American. Baltimore: Johns Hopkins University Press.

[2] Whyte, W. H. (1959). Securing open space for urban American: conservation easements. Washington: Urban Land Institute.

[3] President's (1987). Commission on Americans Outdoors. Americans outdoors: the legacy, the challenge, with case studies. Washington: Island Press.

[4] Michael, S. N., Hull, R. B., \& Zahm, D. L. (2001) Environmental Factors Influencing Auto Burglary: A Case Study. Environment and Behavior, 33(3), 368-388. https://doi.org/10.1177/00139160121973034

[5] Michael, S. N. \& Hull, R. B. (1994). Effects of Vegetation on Crime in Urban Parks. Virginia Polytechnic Institute and
State University, College of Forestry and Wildlife Resources, Department of Forestry, Blacksburg.

[6] Donovan, G. H. \& Prestemon, J. P. (2012). The Effect of Trees on Crime in Portland, Oregon. Environment and Behavior, 44(1), 3-30. https://doi.org/10.1177/0013916510383238

[7] Jiang, Y. \& Zhou, G. (2005). Defensible space and urban public environment design. Journal of Chongqing Jianzhu University, (01), 18-22.

[8] Cai, K. (2008). Fulfilling Crime Prevention in Public Spaces by Urban Design: Britain Experience and Inspiration. Huazhong Architecture, 26(11), 92-95.

[9] Jacobs (1961). The death and life of great American cities. Vintage Books: New York.

[10] Zhao, B. \& Jin, Y. (2012). The history of CPTED theory and the comparison between China and foreign countries. Juvenile delinquency, (03), 34-41.

[11] Unicri (2011). New Energy for Urban Security - Improving Urban Security Through Green Environmental Design: UNICRI, Sense-able City Lab of the Massachusetts's Institute of Technology (MIT).

[12] Cozens, P. M., Saville, G., \& Hillier, D. (2005). Crime prevention through environmental design (CPTED): a review and modern bibliography. Property Management, 23(5), 328-356. https://doi.org/10.1108/02637470510631483

[13] Crewe, K. (2001). Linear Parks and Urban Neighbourhoods: A Study of the Crime Impact of the Boston South-West Corridor. Journal of Urban Design, 6(3), 245-264. https://doi.org/10.1080/13574800120105779

[14] Meng, X. \& Ci, X. (2013). Big data management: concepts, technologies and challenges. Journal of Computer Research and Development, 50(01), 146-169.

[15] Lynch, C. (2008). Big Data: How do your data grow? Nature, (455), 28-29. https://doi.org/10.1038/455028a

[16] Jasny, B. R., Chin, G., Chong, L., \& Vignieri, S. (2011). Again, and Again, and Again ... Science, 334(6060), 1225. https://doi.org/10.1126/science.334.6060.1225

[17] Ciurea, C., Pocatilu, L., \& Filip, F. G. (2020). Using Modern Information and Communication Technologies to Support the Access to Cultural Values. Journal of System and Management Sciences, 10(2), 1-20.

[18] Ongusl, R. W. \& Nyamboga, C. M. (2019). Collecting Development Practices in Using Information Technology: A Comparative Study. Journal of Logistics, Informatics and Service Science, 6(2), 1-22.

[19] Fu, L. \& Dong, Y. (2018). Research on Internet Search Data in China's Social Problems under the Background of Big Data. Journal of Logistics, Informatics and Service Science, 5(2), 55-67.

[20] Ye, Y., Wei, Z., \& Wang, H. (2014). Urban planning response in the Era of big data. Planner, 30(08), 5-11.

[21] Fleischhacker, S. E., Evenson, K. R., Sharkey, J., Pitts, S. B. J., \& Rodriguez, D. A. (2013). Validity of Secondary Retail Food Outlet Data: A Systematic Review. American Journal of Preventive Medicine, 45(4), 462-473. https://doi.org/10.1016/j.amepre.2013.06.009

[22] Ye, Y., Zhang, L., Yan, W., \& Zeng, W. (2018). Measuning Street Greening Quality from Humanistic Perspective: A Large-scale Analysis Based on Baidu Street View Images and Machine Learning Algorithms. Landscape Architecture, 25(08), 24-29.

[23] Lu, Y. (2018). Using Google Street View to investigate the association between street greenery and physical activity. Landscape Urban Plan. https://doi.org/10.1016/j.landurbplan.2018.08.029

[24] Rundle, A. G., Bader, M. D. M., Richards, C. A., Neckerman, K. M., \& Teitler, J. O. (2011). Using Google Street View to Audit Neighborhood Environments. American Journal of Preventive Medicine, 40(1), 94-100. https://doi.org/10.1016/j.amepre.2010.09.034 
[25] Yin, L., Cheng, Q., Wang, Z., \& Shao, Z. (2015). "Big data" for pedestrian volume: Exploring the use of Google Street View images for pedestrian counts. Applied Geography, 63, 337-345. https://doi.org/10.1016/j.apgeog.2015.07.010

[26] Zhang, F., Zhou, B., Liu, L., Liu, Y., Fung, H. H., Lin, H., \& Ratti, C. (2018). Measuring human perceptions of a largescale urban region using machine learning. Landscape Urban Plan, 180, 148-160. https://doi.org/10.1016/j.landurbplan.2018.08.020

[27] Dakak, S. \& Wahbeh, F. (2020). Designing Fast Transportation Network in Damascus: An Approach Using Flow Capturing Location Allocation Model. Journal of Logistics, Informatics and Service Science, 7(1), 58-66.

[28] Zhou, Z. (2015). Research of city greenways' cultural expression pattern: Greenways in Beijing area as an Example. Beijing Forestry University.

[29] Wang, W. (2015). Discussion on the development and construction of greenway landscape in the second ring road of Beijing. Landscape architecture of Beijing, 31(04), 12-20.

[30] Pan, G. \& Wang, X. (2016). Planning and design of Beijing three hills and five gardens greenway system. Journal of Beijing University of Agriculture, 31(02), 102-106.

[31] Li, X., Qi, T., Liu, C., \& Zhang, G. (2018). The research on Analysis Model of landscape Aesthetic Quality: A case of Three Hills and Five Gardens greenway in Beijing. Modern Urban Research, (04), 45-55.

[32] Jeffery, C. R. (1971). Crime Prevention through Environmental Design. Sage, Beverly Hills, CA. https://doi.org/10.1177/000276427101400409

[33] Zhao, B. \& Jin, Y. (2012). The history of CPTED theory and the comparison between China and foreign countries. Juvenile Delinquency, (03), 34-41.

[34] Zhang, Y. \& Yu, H. (2004). Research of City Planning and Landscape Design Strategy Based on CPTED Theory. Chinese \& Overseas Architecture, (01), 100-101.

[35] Maas, J., Spreeuwenberg, P., Van Winsum-Westra, M., Verheij, R. A., de Vries, S., \& Groenewegen, P. P. (2009). Is Green Space in the Living Environment Associated With People's Feelings of Social Safety?. Environment and Planning A, 41(7), 1763-1777. https://doi.org/10.1068/a4196

[36] Wolf, K. L. (2010). Crime and Fear - A Literature Review. Green Cities: Good Health. College of the Environment, University of Washington.

[37] Braga, A. A. \& Bond, B. J. (2008). Policing Crime and Disorder Hot Spots: A Randomized Controlled Trial. Criminology, 46(3), 577-607. https://doi.org/10.1111/j.1745-9125.2008.00124.x

[38] Fisher, B. \& Nasar, J. L. (1995). Fear Spots in Relation to Microlevel Physical Cues: Exploring the Overlooked. Journal of Research in Crime and Delinquency, 32, 214-239. https://doi.org/10.1177/0022427895032002005

[39] Zhang, F., Zhou, B., Liu, L., et al. Measuring human perceptions of a large-scale urban region using machine learning. 2018, 180:148-160 https://doi.org/10.1016/j.landurbplan.2018.08.020

[40] Özgüner, H. \& Kendle, A. D. (2004). Public attitudes towards naturalistic versus designed landscapes in the city of Sheffield (UK). 74(2), 139-157. https://doi.org/10.1016/.landurbplan.2004.10.003

[41] Brown, B. B. \& Altman, I. (1983). Territoriality, Defensible Space and Residential Burglary: An Environmental Analysis. Journal of Environmental Psychology, 3, 203-220. https://doi.org/10.1016/S0272-4944(83)80001-2

[42] Bennett, T. (1989). Burglars' Choice of Targets. The Geography of Crime. Routledge, New York.

[43] Bennett, T. \& Wright, R. (1984). Burglars on Burglary: Prevention and the Offender. Gower, Brookfield, Vermont.

[44] Cromwell, P. F., Olson, J. N., \& Avary, D. W. (1991). Breaking and Entering: An Ethnographic Analysis of Burglary. Sage Publications, Newbury Park, CA.
[45] Crowe, T. D. \& Zahm, D. L. (1994). Crime Prevention through Environmental Design. NAHB Land Development Fall, 22-27.

[46] Li, X., Ratti, C., \& Seiferling, I. (2018). Quantifying the shade provision of street trees in urban landscape: A case study in Boston, USA, using Google Street View. Landscape Urban Plan, 169, 81-91. https://doi.org/10.1016/j.landurbplan.2017.08.011

[47] Gong, F., Zeng, Z., Ng, E., \& Norford, L. K. (2019). Spatiotemporal patterns of street-level solar radiation estimated using Google Street View in a high-density urban environment. Build Environ, 148, 547-566. https://doi.org/10.1016/j.buildenv.2018.10.025

[48] Middel, A., Lukasczyk, J., Maciejewski, R., Demuzere, M., \& Roth, M. (2018). Sky View Factor footprints for urban climate modeling. Urban Climate, 25, 120-134. https://doi.org/10.1016/j.uclim.2018.05.004

[49] Li, X., Zhang, C., Li, W., Ricard, R., Meng, Q., \& Zhang, W. (2015). Assessing street-level urban greenery using Google Street View and a modified green view index. Urban for Urban Gree, 14(3), 675-685. https://doi.org/10.1016/j.ufug.2015.06.006

[50] Yu, Y., Tang, X., Liu, J., \& Lu, S. (2018). Urban Street Health Service Function Based on Mobile Fitness Data. Landscape Architecture, 25(08), 18-23.

\section{Contact information}

Junyi SU, Master

School of Landscape Architecture, Beijing Forestry University,

35 Tsinghua E Road, Beijing, China

E-mail: sjy1996@bjfu.edu.cn

Weida YIN, Associate Professor

(Corresponding author)

School of Landscape Architecture, Beijing Forestry University,

35 Tsinghua E Road, Beijing, China

E-mail: maximusinjapan@hotmail.com

Renfei ZHANG, Master

School of Landscape Architecture, Beijing Forestry University, 35 Tsinghua E Road, Beijing, China

E-mail: 2465253378@qq.com

Xiyao ZHAO, Master

Institution, Beijing Forestry University,

35 Tsinghua E Road, Beijing, China

E-mail: zxy95312@bjfu.edu.cn

Olivier Ngoko CHINKAM, Master

School of Landscape Architecture, Beijing Forestry University,

35 Tsinghua E Road, Beijing, China

E-mail: olivierchinkam@yahoo.com

Hanwen ZHANG, Master

School of Engineering and Applied Science,

University of Pennsylvania,

2930 Chestnut st EVO, Philadelphia, Pennsylvania, 19104, US

E-mail: hwzhang@seas.upenn.edu

Fei LI, Associate professor

School of Landscape Architecture, Beijing Forestry University,

35 Tsinghua E Road, Beijing, China

E-mail: liffei369@qq.com

Le KANG, Master

East China Inventory and Planning Institute of the State Administration of Forestry and Grassland,

Hangzhou, Zhejiang, China

E-mail: hdybhc@163.com 